\title{
Characteristics of cold-warm variation in the Hetao region and its surrounding areas in China during the past 5000 years
}

\author{
M.-Q. Li ${ }^{1,2}$, Q.-S. Ge ${ }^{1}$, Z.-X. Hao ${ }^{1}$, J.-Y. Zheng ${ }^{1}$, and S.-F. He ${ }^{1,2}$ \\ ${ }^{1}$ Institute of Geographical Sciences and Natural Resources Research, Chinese Academy of Sciences, Beijing 100101, China \\ ${ }^{2}$ Graduate School of the Chinese Academy of Sciences, Beijing 100049, China
}

Received: 17 November 2009 - Published in Clim. Past Discuss.: 6 January 2010

Revised: 2 July 2010 - Accepted: 14 July 2010 - Published: 26 July 2010

\begin{abstract}
Using six long-term temperature proxy data series derived from different natural evidences, including pollens and lake-sediments, we reconstructed a temperature series with a 100-yr time resolution for the past $5000 \mathrm{yr}$ in the Hetao region and its surrounding areas. The resulting series suggests that, on a millennial timescale, temperatures in the region were higher than the mean value of the whole series during the 5000 2600 years before present (yr BP) period, and became relatively low comparing with the average temperature of the whole series after $2600 \mathrm{yr} \mathrm{BP}$. Within these two periods, temperature fluctuations comprising numerous short, multi-centennial intervals also existed. A comparison between our reconstructed series and other series in China and across the Northern Hemisphere indicate that, on a longterm scale, cold-warm variations had been in phase across the whole hemisphere during the past 5000 years; on the century to multi-century scale, the beginning and the ending times varied from region to region, thus implying that climate changes did not occur simultaneously in different regions.
\end{abstract}

\section{Introduction}

The reconstruction of temperature series for various historical periods provides important background for understanding the patterns of natural climate variability and improves our ability to assess the anthropogenic role in observed modern climate change. A number of previous studies have thus focused on climate change of past few centuries to millennium by means of modeling experiments that employ estimated climate forcing and empirical reconstructions based on climate proxy data (Mann et al., 2003).

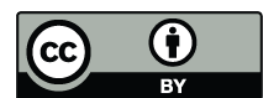

Correspondence to: Q.-S. Ge

(geqs@igsnrr.ac.cn)
Several recent studies emphasized spatial reconstruction of climate based on techniques for reconstruction of multivariate climate fields (Mann et al., 1998, 1999, 2003, 2008; Luterbacher et al., 2002; Evans et al., 2003; Moberg et al., 2005). These spatial reconstructions have focused on the climate changes of the past few centuries to two millennia on a global scale. In China, some scholars have reconstructed temperature series using an integrated method (Wang et al., 1998, 2007; Yang et al., 2002; Ge et al., 2006). The uncertainty of reconstructing climatic changes can be reduced by using the method.

the Hetao region and its surrounding areas lie in the transition zone between agriculture and animal husbandry in northern China and include areas of the Mu Us, Hobq, and UlaanBuh deserts. The Hetao region has an acutely vulnerable ecological environment and is sensitive to climate change. Thus, it is an ideal area for studying both east-Asian monsoon changes and global climate changes; to do so, it is important to reconstruct the past climatic variations of this region.

During the past few years, a lot of long-term, highresolution climate proxy reconstructions with reliable millennial-scale variability have been produced for this region, which provide us proxy data to reconstruct climate change by using the integrated method. In our study, the characteristics of cold-warm variation in Hetao region and its surrounding area for the past $5000 \mathrm{yr}$ are analyzed by using six long-term reconstructed temperature proxy series (Fig. 1).

\section{Materials}

Of the many recent studies on historic temperature variations in the Hetao region carried out, most are qualitative analyses on a century timescale; quantitative analyses on multicentury or millennial scales are relatively scarce. Following

Published by Copernicus Publications on behalf of the European Geosciences Union. 


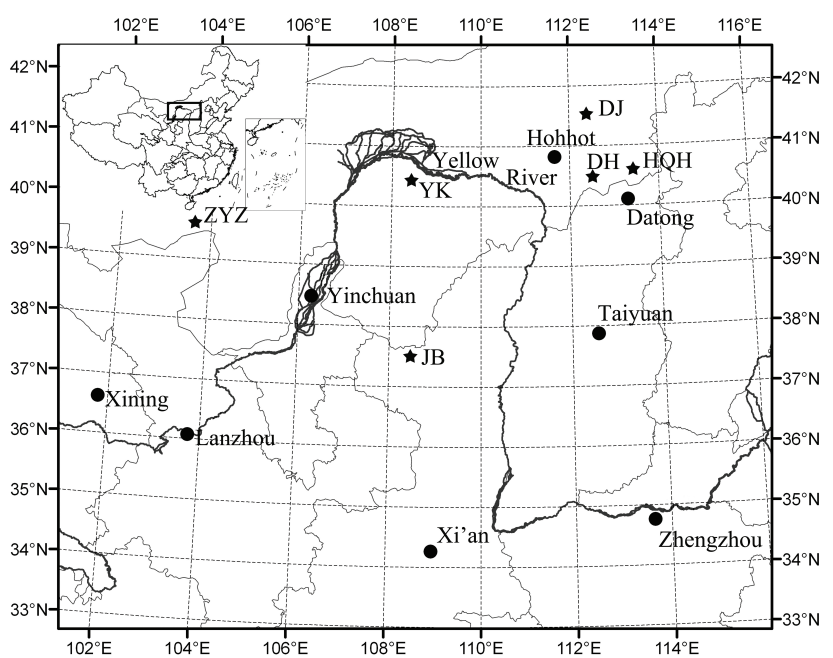

Fig. 1. Distribution map for six locations of proxy climate records. (Stars=the site of proxy climate records; dots=primary cities).

are the six long-term temperature proxy series (Table 1) selected from recent publications used in our study:

- The average July-temperature series in the Daihai Lake (DH) reconstructed quantitatively by using model based on pollens (Xu et al., 2003).

- The oxygen isotope series of a salt lake in Yikezhaomeng, Inner Mongolia (YK) (Qian et al., 2002), which indicates temperature changes with lower than $100 \mathrm{yr}$ temporal resolution.

- The annual average temperature series, which was reconstructed by using model based on pollens in Diaojiaohaizi Lake, Inner Mongolia (DJ) (Shi et al., 2003).

- The total organic-carbon content (TOC) series in Jingbian County (JB) (Xiao et al., 2002). TOC and Md from Jingbian Section are reliable paleo-temperature proxies, in that Jingbian Section contains a higher TOC and a lower Md value during warm/wet period and vice versa (Xiao et al., 2002).

- The magnetic susceptibility series in Huangqihai Lake (HQH) (Shen et al., 2006), which reflects climate changes between the warm-wet and cold-arid periods; therefore the magnetic susceptibility can be as a paleotemperature proxy.

- The carbonate-content series in Zhuyeze Lake (ZYZ) (Long et al., 2007) also reflects climate changes between the warm-wet and cold-arid periods.

Locations for these six series are shown in Fig. 1. The timescales of the six series are more than $5000 \mathrm{yr}$ and are well-dated. Among the six series, DH and DJ showed temperature changes; the others depict proxy temperature changes with different proxy records. 6 reconstructions from different proxy archives represent temperature changes. According to instrumental temperature records, the temperature changes of each region which 6 selected series locate can explain between $83 \%$ and $94 \%$ of annual temperature variability of the study area in 1951-2007. But the six series have different temporal resolution, and there are difference about climate change revealed by the six series in terms of type of natural archive and their correlation with temperature.

For the sake of transferring and comparing data, we used the annual surface-temperature grid-point ( 1 latitude $\times 1$ longitude) data set in 1951-2007 in China (http://cdc.cma.gov. $\mathrm{cn} /$ ) for analysis. This data set was obtained using the Spatial Kriging Interpolation Method based on average monthly temperature and DEM (digital elevation model) materials of 731 stations throughout China.

\section{Methods}

Two ways to reconstruct regional paleo-temperature series under the constraint of insufficient data were commonly used in previously published articles: computing the average of all available proxy series in a study area (Jones et al., 1999; Crowley and Lowery, 2000) using a data set that is relatively small and heterogeneous; merging proxy records of several sub-regions by a specific area weighting (Wang et al., 2000; Yang et al., 2002). The latter method has recently been widely used for regional, hemispheric, and global climate reconstructions (Bradley et al., 1993; Jones et al., 1998; Mann et al., 1998, 1999, 2003; Moberg et al., 2005). This method emphasizes a synthesis of different types of proxies derived from various local regions having differing temporal resolutions. The integrated results show some important climate features not derived from one type of proxy records or from proxies with identical temporal resolutions. To some extent, the multi-proxy analysis method can thus reduce uncertainties in proxy-based climate reconstructions.

Taking the actual background of the study area into consideration, we developed an improved method to reconstruct the regional temperature series of the small Hetao region.

First we calculated the series of annual temperatures for the whole region (WT) of Hetao and neighboring areas according to the surface annual-temperature grid data during 1951-2007 for China (Eq. 1). We next calculated the correlation between WT and the annual temperature series in each grid area; this correlation is considered as a contribution to the entire region. The total value (TV) is the sum of the grid contributions provided by each of the series (Eq. 2); the weighted value is the ratio of the contribution value of one series to the TV (Eq. 3). Finally, based on the weighted values of the grids, the following weighted-average equation 
Table 1. Information regarding the six series applied.

\begin{tabular}{|c|c|c|c|c|c|c|c|}
\hline No. & $\begin{array}{l}\text { Site or } \\
\text { region }\end{array}$ & $\begin{array}{l}\text { Proxy type } \\
\text { and interpretation }\end{array}$ & $\begin{array}{l}\text { Resolution } \\
\text { (years' time span) }\end{array}$ & $\begin{array}{l}\text { No. of } \\
{ }^{14} \mathrm{C} \text { dates }\end{array}$ & $\begin{array}{l}\text { First, last year } \\
\text { (yr BP) }\end{array}$ & $\begin{array}{l}\text { Age } \\
\text { type }\end{array}$ & $\begin{array}{l}\text { Calibrated time } \\
\text { (Cal. yr BP) }\end{array}$ \\
\hline 1 & $\begin{array}{l}\text { Daihai Lake (DH) } \\
40^{\circ} \mathrm{N}, 112^{\circ} \mathrm{E}\end{array}$ & Pollen, July $T^{(1)}$ & $23-158$ & 8 & $12000-0$ & Cal. (2) & $12000-0$ \\
\hline 2 & $\begin{array}{l}\text { Yikezhaomeng } \\
\text { salt lake (YK) } \\
39^{\circ} \mathrm{N}, 109^{\circ} \mathrm{E}\end{array}$ & $\begin{array}{l}\text { Lake sediment, } \\
\delta^{18} \mathrm{O}\end{array}$ & $>100$ & 5 & $16000-0$ & ${ }^{14} C^{(3)}$ & $19091-0$ \\
\hline 3 & $\begin{array}{l}\text { Diaojiaohaizi Lake (DJ) } \\
41^{\circ} \mathrm{N}, 112^{\circ} \mathrm{E}\end{array}$ & $\begin{array}{l}\text { Pollen; } \\
\text { annual average } T\end{array}$ & 100 & 4 & $10000-2000$ & ${ }^{14} \mathrm{C}$ & $11471-1946$ \\
\hline 4 & $\begin{array}{l}\text { Jingbian County (JB) } \\
37^{\circ} \mathrm{N}, 108^{\circ} \mathrm{E}\end{array}$ & $\begin{array}{l}\text { Total Organic- } \\
\text { Carbon }\end{array}$ & 100 & 11 & $10000-0$ & Cal. & $10000-0$ \\
\hline 5 & $\begin{array}{l}\text { Huangqihai Lake }(\mathrm{HQH}) \\
41^{\circ} \mathrm{N}, 113^{\circ} \mathrm{E}\end{array}$ & $\begin{array}{l}\text { Lake sediment; } \\
\text { magnetic susceptibility }\end{array}$ & $<100$ & 4 & 9000-2000 & ${ }^{14} \mathrm{C}$ & $10200-1946$ \\
\hline 6 & $\begin{array}{l}\text { Zhuyeze Lake (ZYZ) } \\
39^{\circ} \mathrm{N}, 103^{\circ} \mathrm{E}\end{array}$ & $\begin{array}{l}\text { Lake sediment; } \\
\text { content of carbonate }\end{array}$ & $<100$ & 11 & $9000-3000$ & Cal. & $9000-3000$ \\
\hline
\end{tabular}

Notes: (1) $T$ represents temperature; (2) Cal. represents the series chronological control provided by calendar ages; (3) ${ }^{14} \mathrm{C}$ represents the series as chronologically controlled by ${ }^{14} \mathrm{C}$ ages.

was adopted to combine the six series into the whole regional temperature series (Eq. 4). The equations are as follows:

$W T=\sum_{i=1}^{n} T_{i} / n$

Where WT is the series of annual temperatures for the whole region according to the surface annual-temperature grid data during 1951-2007 for China; $T_{i}$ is the temperature of each grid and $n$ is the numbers of grid.

$T V=\sum_{i=1}^{n} r_{i}$

Where TV is the sum of $r$ and $r_{i}$ is the correlation between WT and $T_{i}$.

$S_{i}=r_{i} / T V$

Where $S_{i}$ is the area's weighted value.

$T_{w}=\sum_{i=1}^{m} T_{i} S_{i}$

Where $T_{w}$ is the whole regional temperature, $T_{i}$ is the temperature of each sub-region and $m$ is the numbers of subregion.

Before averaging, each series is standardized; this gives the relative amplitude of temperature change, as shown in Fig. 2. The three steps of the method for standardizing are as follows:

(1) Selecting samples-According to the correlative papers, the reconstructed data of all but the DH series were obtained by digitizing. All of the abrupt climate change points in each series were taken as random samples to reconstruct the whole region series.

(2) Calibrating the ${ }^{14} \mathrm{C}$ ages into calendar ages-using the calib5.0 program (Stuiver et al., 1998), the six series were all converted to calendar chronological series.

(3) Making the series dimensionless-each series was standardized to a dimensionless series that reflected the climate variation amplitude.

With respect to the time resolution, three of the six series we selected are higher than $100 \mathrm{yr}$, two are about $100 \mathrm{yr}$, and one is lower than $100 \mathrm{yr}$ (Table 1). Accordingly, the past 5000 yr was divided into $100-y r$ intervals. For every series we selected, we calculated the average of all data within each 100-yr period if the series resolution was not lower than $100 \mathrm{yr}$ and by linear interpolation between existing data if the series resolution was lower than $100 \mathrm{yr}$. Finally, a series that indicates temperature variation (weighted average, WA) was acquired according to the methods previously described (as depicted in Fig. 3).

\section{Results and discussion}

Figure 3 shows that the change trend of CA (arithmetic average) is very consistent with that of WA, with the only differences being the values of original data. In the past $5000 \mathrm{yr}$ and on the millennial scale, variations in temperature were warm in 5000 2600 cal yr BP and were colder after $2600 \mathrm{cal}$ yr BP. Within these two periods, the temperature fluctuated, and there existed numerous short, multi-century sub-stages. We divided the $5000 \mathrm{yr}$ into following seven periods according to cold-warm variations. 


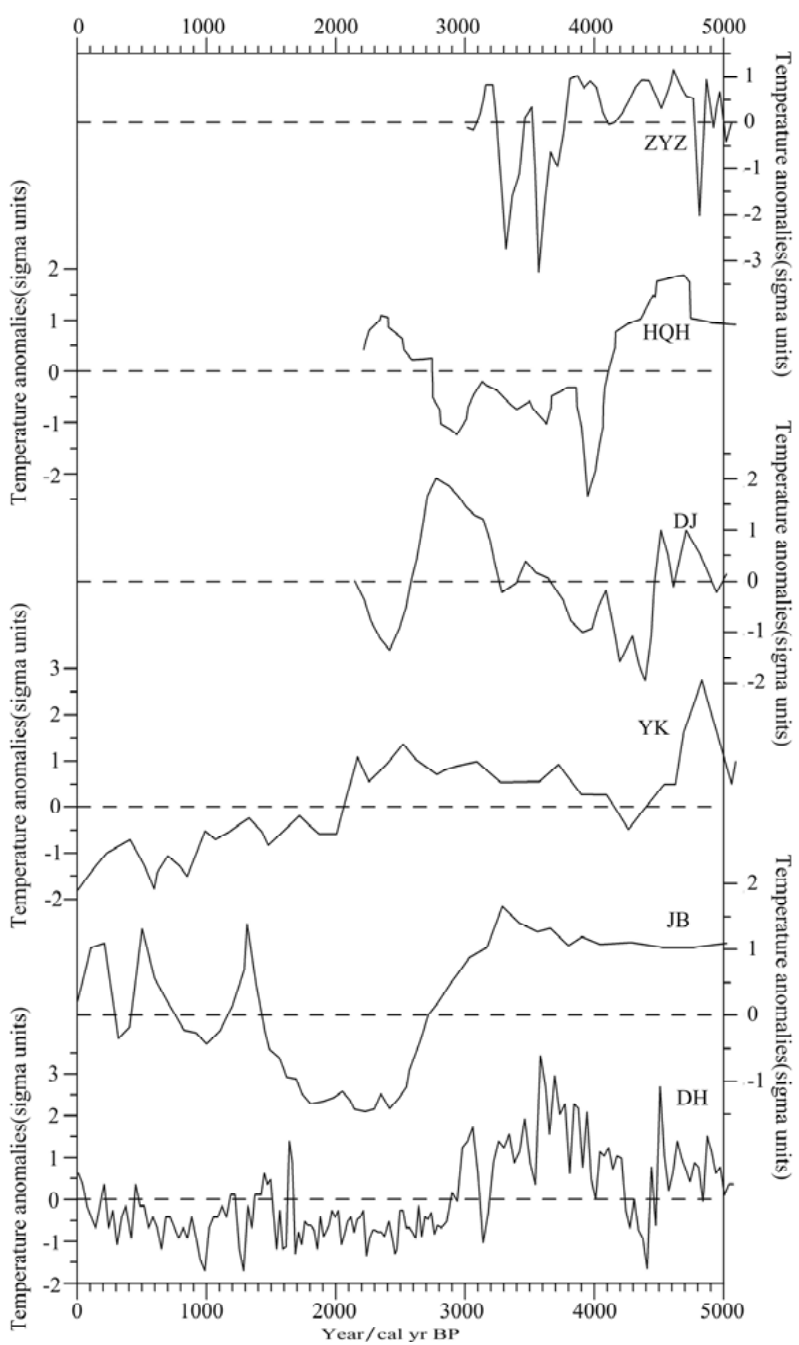

Fig. 2. Standardized 5000-yr regional temperature series for Hetao region and its vicinity.

1. $5000 \sim 4500 \mathrm{yr}$ BP: This period was the end of the Holocene Megathermal Maximum Age. The temperature was higher than the mean value of the whole series in Hetao and its neighboring areas. Other domestic studies have validated the existence of this warm sub-stage. The temperature series reconstructed by Chu (1973) showed that it was warm in China during this period, as well as it was warm and humid in the Poyanghu Lake area of Jiangxi Province (Peng et al., 2003), in the Zhengzhou area of Henan Province (Wang et al., 2004), in the Hanihu Lake area of Jilin Province (Cui et al., 2006), and in Dunde ice core in Qinghai Province (Yao et al., 1992). These facts are also corroborated by many worldwide studies. It was proved that the climate during this period was warm in the north of Iceland (Axford et al., 2007) and in the area of the North Atlantic (Bond et al., 2001).

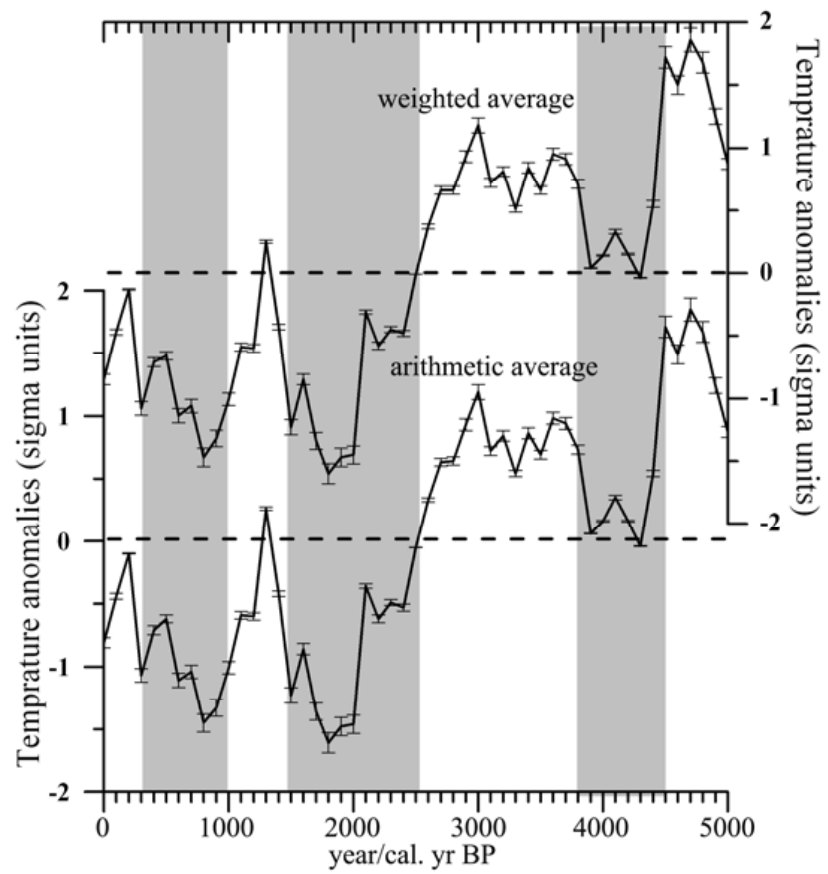

Fig. 3. Temperature reconstructions in Hetao region and neighboring area.

2. $4500 \sim 3900$ yr BP: The temperature decreased in the study area and reached the lowest of during this time period at $4300 \mathrm{cal} \mathrm{yr} \mathrm{BP}$. Other facts suggest that the cold event was global. Jin et al. (2002) proved that the cold event happened in the north China during 4800 4200 cal yr BP; Zhang et al. (1997) found out that the mean temperature during that cold event period was about $3{ }^{\circ} \mathrm{C}$ lower than the present temperature in the transition zone between agriculture and husbandry areas in China; Lü (1991) deduced that the climate obviously turned cold at about $4.2 \mathrm{kyr} \mathrm{BP}\left({ }^{14} \mathrm{C}\right)$ in the north of China; Shao et al. (2006) proved a cold and arid event at $4.3 \mathrm{cal} \mathrm{kyr}$ BP in the Shennongjia area of Hubei Province by means of an oxygen isotope series in a stalagmite; Bond et al. (1997) discovered an ice-floating event in the North Atlantic Ocean during this time period; and Hong et al. (2003) found that the Indian monsoon weakened suddenly at about $4.3 \mathrm{kyr}$ BP.

3. $3900 \sim 2600$ cal yr BP: The temperature was relatively high compare with the mean value of the whole series (Fig. 3). In addition, the $\delta^{18} \mathrm{O}$ and pollens appearing in peat in Taishizhuang village gave evidence of a very warm event during $4.2 \sim 3.38 \mathrm{cal} \mathrm{kyr} \mathrm{BP}$ in the northern Huabei area of China (Jin et al., 2002); the Indian summer monsoon was very strong at the same time (Hong et al., 2003); the climate was very warm at about 2.5 kyr BP in Fennoscandia region, Finland (Seppä et al., 2002). 
4. $2600 \sim 1450$ cal yr BP: The temperature decreased rapidly and was lower than the mean value of the whole series (Fig. 3). Parallel evidence abounds: The lake-sediment record in Jiaming Lake showed that the climate turned cold after $2.2 \mathrm{kyr}$ BP in southern Taiwan (Luo et al., 1997); The climate was also cold during $2550 \sim 1211 \mathrm{yr}$ BP in Ulaan-Buh Desert of China (Jia et al., 2003); The strata in Hunshandake Desert of China show an abundance of Aeolian sand at about $1.8 \sim 1.3$ cal kyr BP, thus giving evidence of a cold climate (Jin et al., 2004); The Guliya ice core and tree-ring records in China show that the climate was cold at $0 \mathrm{AD}$ (Yao et al., 2001); The winter half-year temperature was relatively low during $1700 \sim 1400 \mathrm{yr} \mathrm{BP}$ in eastern China (Ge et al., 2003); The yearly average temperature was low in the Tibet plateau region during the period (Yang et al., 2003); A cold event during 1.8 1.4 kyr BP had been recorded in the southern deep sea off Iceland (Bianchi et al., 1999); An ice-floating event appeared in the North Atlantic Ocean at 1.4 kyr BP (Bond et al., 1997).

5. $1450 \sim 1000$ cal yr BP: The climate was relatively warm compare with the temperature of its adjacent periods but less so than the degree of warmth at $5000 \mathrm{cal}$ yr BP. This period corresponded to the Medieval Warm Period. Following are $p$ proofs that give examples: A warming event happened in Daihai Lake in the southern part of the study region during 1.2 0.9 kyr BP (Jin et al., 2002); The Dunde ice core indicated that there was a climate warming phase during the 13th century (Yao et al., 1992); The Guliya ice core recorded a warm event in 1250 1150 cal yr BP (Yao et al., 1996); At the Chesapeake Dam, the Medieval Warm Period began at 1150 cal yr BP (Cronin TM et al., 2003), which was earlier than the period began in other areas in the world.

6. $1000 \sim 300$ cal yr BP: the temperature decreased again. this period includes the Little Ice Age. Temperature of the lake water of Daihai Lake was low during 2010$300 \mathrm{yr}$ BP (Shen et al., 2002). Aeolian sand deposited in Hunshandake Desert during 700-200yr BP produced a record of the cold event, which took place at about 400 yr BP (Jin et al., 2004).

7. $300 \mathrm{cal}$ yr BP to present: The climate has been warming. Shen et al. (2002) found out that the water temperature in Daihai Lake had been rapidly warming since $300 \mathrm{yr} \mathrm{BP}$, increasing from $16.2^{\circ} \mathrm{C}$ to $17.5^{\circ} \mathrm{C}$.

In addition, the correlation coefficient of temperature records of Zhangye meteorological station and Hetao region from 1956 to 2009 is 0.936 , and the tree-ring width and temperature data from Zhangye meteorological station have a closer relation (Liu et al., 2007). Therefore, the tree-ring width indicated the temperature changes in Qilian Mountain.

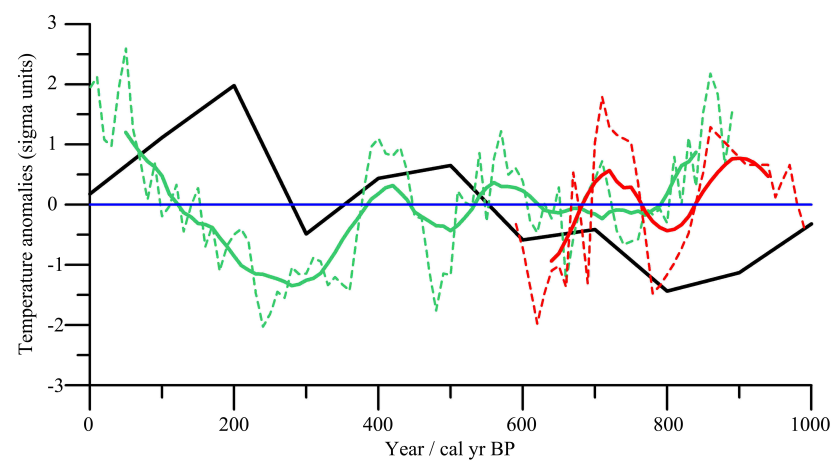

Fig. 4. Comparison of three temperature reconstructions for China. Black curve: temperature series reconstructed in the paper; Green dashed line: 10-yr average temperature changes reconstructed by using tree-ring in Qilian Mountain (Liu et al, 2007); Green curve: 100 -yr smoothing average temperature records in Qilian Mountain; Red dashed line: 10 -yr average temperature record reconstructed by using history record and natural evidence in eastern part of North West China; and Red curve (Hao et al., 2009): 100-yr smoothing average temperature record in eastern part of North West China.

A comparison of series reconstructed for the Hetao and its surrounding area with the Qilian mountain temperature series (Liu et al., 2007) from tree-ring, and temperature reconstruction for western north China from history documents(Hao et al., 2009) in Fig. 4. The Figure4 shows that the temperature changes of the Hetao and its surrounding area shows good agreement with that of the Qilian Mountain and of eastern part of North West China. But there are differences in some stages, such as about $500 \mathrm{yr} \mathrm{BP}$, it may be induced by the difference between tree ring and other proxy archives, because generally in this region, the width of tree ring is more sensitive to low temperature, but not for the high temperature.

\section{Conclusions}

The air temperature, on the millennial scale variation, was relatively high compare with the mean value of the whole series during 5000 2600 cal yr BP and decreased after 2600 cal yr BP. Many temperature fluctuations took place during those two periods. During the periods of $5000 \sim 4500$ cal yr BP, $3900 \sim 2600$ cal yr BP, $1450 \sim 1000 \mathrm{cal} \mathrm{yr} \mathrm{BP}$, and $300 \mathrm{cal} \mathrm{yr} \mathrm{BP}$ to present, the climate was warm; while during the periods of $\quad 4500 \sim 3900 \mathrm{cal} \mathrm{yr} \mathrm{BP}, \quad 2600 \sim 1450 \mathrm{cal} \mathrm{yr} \mathrm{BP,}$ and $1000 \sim 300$ cal yr BP, the temperature decreased.

The cold-warm variation of climate on long-term scale disclosed by the reconstructed series described in this paper took place in phase with that proved in other global research efforts. However, on the century to multi-century scale, the beginning and the ending times varied from region to region, thus implying that climate changes did not occur simultaneously in different regions, because the climate are affected 
by regional atmospheric circulation, regional landform, et al.. Taking China as an example, according to modern instrumental data, the domain of China can be divided into 5 climate regions (Ge et al., 2010) and the variations of annual mean temperature were mainly determined by variations winter-half year temperature. Our study area lies in the east of the northwest region. The temperature of winter-half year is affected by the winter monsoon. The winter monsoon has different effect on the 5 regions because of the Qinghai-Tibet plateau, mountains and the distance from Siberian area which is one of the original sources of cold wave, therefore there are differences in temperature change in this 5 regions.

The steps reconstructing series are as follows:

Firstly, we standardized the selected 6 series respectively, equation is as follows:

$T_{i}=\frac{x_{i}-\bar{x}}{\sigma}$

Where $T_{i}$ is standard score, $x_{i}$ is the ith value in the origin series, $\bar{x}$ is the average of the origin series, and $\sigma$ is standard deviation of the origin series.

Secondly, we synthesized a series with the 6 standardized series by using the methods of "arithmetic average" and "weighted average". The equations are follows:

$$
\begin{aligned}
T_{a} & =\sum_{i=1}^{m} T_{i} / m \\
T_{w} & =\sum_{i=1}^{m} T_{i} S_{i}
\end{aligned}
$$

Where $T_{a}$ is arithmetic average value, $T_{w}$ is weighted average value and $S_{i}$ is the area's weighted value.

Acknowledgements. We are grateful to Liangying Sun, Karen L. Lew and Gregory Pierce for the comments on an early draft of the manuscript. We thank M. F. Loutre and five anonymous reviewers who provided helpful comments on the manuscript. This research was supported by grants to IGSNRR from the National Natural Science Foundation of China (40625002), Chinese Academy of Sciences (KZCX2-YW-315).

Edited by: M.-F. Loutre

\section{References}

Axford, Y., Miller, G. H., Geirsd' ottir, A'., et al.: Holocene temperature history of Northern Iceland inferred from subfossil midges, Quaternary Sci. Rev., 26, 3344-3358, 2007.

Bianchi, G. G. and Mccave, I. N.: Holocene periodicity in North Atlantic climate and deep-ocean flow, south of Iceland, Nature, 397, 515-516, 1999.

Bond, G. C. and Showers, W.: A pervasive millennial-scale cycle in the North Atlantic Holocene and glacial climate, Science, 278, 1257-1265, 1997.
Bond, G., Kromer, B., Beer, J., et al.: Persistent solar influence on North Atlantic climate during the Holocene, Science, 294, 2130 2136, 2001.

Bradley, R. S. and Jones, P. D.: "Little ice age" summer temperature variations: their nature and relevance to recent global warming trends, The Holocene, 3, 367-376, 1993.

Chen, C.-T. A., Lan, H.-C., Lou, J.-Y., et al.: The dry Holocene megathermal in Inner Mongolia, Palaeogeogr. Palaeocl., 193, 181-200, 2003.

Chu, K. C.: A preliminary study on the climatic fluctuation during the last 5000 years in China, Sci. Sinica, XVI, 226-256, 1973.

Cronin, T. M., Dwyer, G. S., Kamiya, T., et al.: Medieval warm period, little ice age and 20th century temperature variability from Chesapeake Bay, Global Planet. Change, 36, 17-29, 2003.

Crowley, T. J. and Lowery, T. S.: How warm was the MedievalWarm Period?, Ambio, 29, 51-54, 2000.

Cui, M. L., Luo, Y. L., and Sun, X. J.: Paleovegetational and paleoclimatic changes in Ha'ni Lake, Jilin since 5 ka BP, Mar. Geol Quat. Geol., 26, 117-122, 2006.

Ge, Q. S., Wang, S. B., and Zheng, J. Y.: Reconstruction of temperature series in China for the last 5000 yr, Prog. Nat. Sci., 16, 838-845, 2006.

Ge, Q. S., Zheng, J. Y., Fang, X. Q., et al.: Temperature changes of winter-half-year in Eastern China during the past $2000 \mathrm{yr}$, The Holocene, 22, 933-940, 2003.

Ge, Q.-S., Zheng, J.-Y., Hao, Z.-X., et al.: temperature variation through 2000 years in China: An Uncertainty Analysis of Reconstruction and regional difference, Geophys. Res. Lett., 37, L03703, doi:10.1029/2009GL041281, 2010.

Hao, Z. X., Ge, Q. S., and Zheng, J. Y.: Temperature variations during the song and Yuan Dynasties (960 1368 AD) in the eastern part of North West China. Quat. Sci., 29, 871-879, 2009.

Hong, Y. T., Hong, B., Lin, Q. H., et al.: Grain size of quartz as an indicator of winter monsoon strength on the Loess Plateau of central China during Holocene, Earth Planet. Sci. Lett., 211, 371-380, 2003.

Jia, T. F., Yin, S., He, Y., et al.: Holocene sediment texture and its environment meaning of Donghaizi Lake in Ulan Buh Desert, J. Desert Res., 23, 165-170, 2003.

Jin, G. Y. and Liu, T. S.: Mid-Holocene climate change in North China, and the effect on cultural development, Chinese Sci. Bull., 47, 408-413, 2002.

Jin, H. L., Su, Z. Z., Sun, L. Y., et al.: Holocene climatic change in Hunshandake Desert, Chinese Sci. Bull., 49, 1730-1735, 2004.

Jin, Z. D., Shen, J., Wang, S. M., et al.: The medieval warm period in the Daihai area, J. Lake Sci., 14, 209-216, 2002.

Jones, P. D., Briffa, K. R., Barnett, T. P., et al.: High resolution palaeoclimatic records from the last millennium: interpretation, integration and comparison with general circulation model control-run temperatures, The Holocene, 8, 445-471, 1998.

Jones, P. D., Osborn, T. J., and Briffa, K. R.: Estimating sampling errors in larger-scale temperature averages, J. Climatol., 10, 2548-2568, 1999.

Liu, X. H., Shao, X. M., Zhao, L. J., et al.: Dendroclimatic temperature record derived from tree- ring width and stable carbon isotope chronologies in the Middle Qianlian Mountains, China. Arct. Antarct. Alp. Res., 39, 651-657, 2007.

Long, H., Wang, N. A., Li, Y., et al.: Mid-Holocene climate variations from lake records of the east Asian monsoon margin: a 
multi-proxy and geomorphological study, Quat. Sci., 27, 371381, 2007.

Lu, H. Y.: Grassland culture and climate change in Northern temperature area since Neolithic Age, Cult. Relic Prot. Archaeol., 3, 44-50, 1991.

Luo, J. Y. and Chen, C. T. A.: Paleoclimatological and paleoenvironmental records since 4000 a BP in sediments of alpine lakes in Taiwan, Sci. China Ser. D, 40, 424-431, 1997.

Mann, M. E. and Jones, P. D.: Global surface temperatures over the past two millennia, Geophys. Res. Lett., 30, 1820-1823, 2003.

Mann, M. E., Bradley, R. S., and Hughes, M. K.: Global-scale temperature patterns and climate forcing over the past six centuries, Nature, 392, 779-787, 1998.

Mann, M. E., Bradley, R. S., and Hughes, M. K.: Northern Hemisphere temperatures during the last millennium: Inferences, uncertainties and limitations. Geophys. Res. Lett., 26, 759-762, 1999.

Mann, M. E., Zhang, Z. H., Hughes, M. K., et al.: Proxy-based reconstructions of hemispheric and global surface temperature variations over the past two millennia, Proc. Natl. Acad. Sci. USA, 105, 13252-13257, 2008.

Moberg, A., Sonechkin, D. M., Holmgren, K., et al.: Highly variable Northern Hemisphere temperatures reconstructed from lowand high-resolution proxy data, Nature, 433, 613-617, 2005.

Peng, H. X., Shi, C. Y., Wei, Y., et al.: Organic carbon stable isotope records of climate evolution in Poyang Lake in the past $5 \mathrm{ka}$ years, J. Cent. China Normal Univ. Nat. Sci., 37, 123-125, 2003.

Qian, Z. H., Kenneth, J. H., and Yuan, Z.: Kataglacial age of quaternary period and climatic characteristics of Holocene epoch - a record of carbon isotope from Yanhaizi Ya02 borehole in Yileague of Inner Mongolia, Geol. Chem. Mineral., 24, 96-101, 2002.

Sepp“ a, H. and Birks, H. J. B.: Holocene climate reconstruction from the Fennoscandian treeline area based on pollen data from Toskaljavri, Quaternary Res., 57, 191-199, 2002.

Shao, X. H., Wang, Y. J., Cheng, H., et al.: Long-term trend and abrupt events of the Holocene Asian monsoon inferred from a stalagmite $\delta 180$ record from Shennongjia in Central China, Chinese Sci. Bull., 51, 221-228, 2006.

Shen, H. Y., Jia, Y. L., Li, X. S., et al.: Environmental change inferred from distribution of $\mathrm{Rb}$ and $\mathrm{Sr}$ in different grain size fractions from lacustrine sediments in Huangqihai Lake, Inner Mongolia, Acta Geogr. Sin., 61, 1208-1217, 2006.

Shen, J., Matsumoto, R., Wang, S. M., et al.: Quantitative reconstruction of the lake water paleotemperature of Daihai Lake, Inner Mongolia, China and its significance in paleoclimate, Sci. China Ser. D, 45, 792-800, 2002.

Shi, P. J. and Song, C. Q.: Palynological records of environmental changes in the middle part of Inner Mongolia, China, Chinese Sci. Bull., 48, 1433-1438, 2003.
Stuiver, M., Reimer, B., and Braziunas, T.: High-precision radiocarbon age calibration for terrestrial and marine samples, Radiocarbon, 49, 1127-1151, 1998.

Wang, S. W. and Gong, D. Y.: Enhancement of the warming trend in China, Geophys. Res. Lett., 27, 2581-2584, 2000.

Wang, S. W., Wen, X. Y., Luo, Y., et al.: Reconstruction of temperature series of China for the last $1000 \mathrm{yr}$, Chinese Sci. Bull., 52, 3272-3280, 2007.

Wang, S. W., Ye, J. L., and Gong, D. Y.: Climate in China during the little ice age, Quat. Sci., 1, 54-64, 1998.

Wang, X. L. and He, Y.: Climate change from 7000 a BP in Xishan Mountain of Zhengzhou by analysis of magnetic susceptibility, J. Beijing Norm. Univ. Nat. Sci., 40, 133-136, 2004.

Xiao, J. L., Nakamura, T., Lu, H. Y., et al.: Holocene climate changes over the desert/loess transition of north-central China, Earth Planet. Sci. Lett., 197, 11-18, 2002.

Xiao, J. L., Xu, Q. H., Nakamura, T., et al.: Holocene vegetation variation in the Daihai Lake region of north-central China: a direct indication of the Asian monsoon climatic history, Quaternary Sci. Rev., 23, 1669-1679, 2004.

Xu, Q. H., Xiao, J. L., Nakamura, T., et al.: Quantitative reconstructed climatic changes of Daihai Basin by pollen data, Marine Geol. Quat. Geol., 23, 99-108, 2003.

Yang, B.: Climate history of the Tibetan Plateau during the last two millennia, Adv. Earth Sci., 18, 285-291, 2003.

Yang, B., Braeuning, A., and Johnson, K. R.: General characteristics of temperature variation in China during the last two millennia, Geophys. Res. Lett., 29, 381-384, 2002.

Yang, B., Braeuning, A., and Shi, Y. F.: Late Holocene temperature fluctuations on the Tibetan Plateau, Quaternary Sci. Rev., 22, 2335-2344, 2003.

Yao, T. D. and Thompson, L. G.: Dunde ice core records and temperature variation in the past $5 \mathrm{ka}$, Sci. China Ser. B, 10, 10891093, 1992.

Yao, T. D., Thompson, L. G., Qin, D. H., et al.: Variations in temperature and precipitation in the past 2000 a on the Xizang (Tibet) Plateau - Guliya ice core record, Sci. China Ser. D, 39, 425433, 1996.

Yao, T. D., Yang, M. X., and Kang, X. C.: Comparative study of the climate change in the past $2000 \mathrm{yr}$ by using ice core and tree ring records, Quat. Sci., 21, 514-519, 2001.

Zhang, L. S., Fang, X. Q., Ren, G. Y., et al.: Environmental change in the north China farming grazing transitional zone, Earth Sci. Front., 4, 127-136, 1997. 